\title{
Subclinical Ulnar Neuropathy at the Elbow in Diabetic Patients
}

\author{
Ji Eun Jang, MD, Yun Tae Kim, MD, Byung Kyu Park, MD, \\ In Yae Cheong, MD, Dong Hwee Kim, MD
}

Department of Physical Medicine and Rehabilitation, Korea University College of Medicine, Seoul, Korea

\begin{abstract}
Objective To demonstrate the prevalence and characteristics of subclinical ulnar neuropathy at the elbow in diabetic patients.

Methods One hundred and five patients with diabetes mellitus were recruited for the study of ulnar nerve conduction analysis. Clinical and demographic characteristics were assessed. Electrodiagnosis of ulnar neuropathy at the elbow was based on the criteria of the American Association of Neuromuscular \& Electrodiagnostic Medicine (AANEM1 and AANEM2). The inching test of the ulnar motor nerve was additionally performed to localize the lesion.

Results The duration of diabetes, the existence of diabetic polyneuropathy (DPN) symptoms, the duration of symptoms, and HbAlC showed significantly larger values in the DPN group $(\mathrm{p}<0.05)$. Ulnar neuropathy at the elbow was more common in the DPN group. There was a statistically significant difference in the number of cases that met the three diagnostic criteria between the no DPN group and the DPN group. The most common location for ulnar mononeuropathy at the elbow was the retrocondylar groove.

Conclusion Ulnar neuropathy at the elbow is more common in patients with DPN. If the conduction velocities of both the elbow and forearm segments are decreased to less than $50 \mathrm{~m} / \mathrm{s}$, it may be useful to apply the AANEM2 criteria and inching test to diagnose ulnar neuropathy.
\end{abstract}

Keywords Diabetes mellitus, Diabetic polyneuropathy, Ulnar neuropathy, Elbow, Entrapment

\section{INTRODUCTION}

Diabetic polyneuropathy (DPN) in patients with diabetes mellitus is a heterogeneous disease that involves

Received June 10, 2013; Accepted September 6, 2013

Corresponding author: Dong Hwee Kim

Department of Physical Medicine and Rehabilitation, Korea University Ansan Hospital, 123 Jeokgeum-ro, Danwon-gu, Ansan 425-707, Korea Tel: +82-31-412-5330, Fax: +82-31-412-4215, E-mail: rmkdh@korea.ac.kr

(c) This is an open-access article distributed under the terms of the Creative Commons Attribution Non-Commercial License (http://creativecommons. org/licenses/by-nc/3.0) which permits unrestricted noncommercial use, distribution, and reproduction in any medium, provided the original work is properly cited.

Copyright () 2014 by Korean Academy of Rehabilitation Medicine various parts of the nervous system thus producing a variety of clinical symptoms. Some of the most common types of neuropathies are distal symmetric sensorimotor neuropathies and autonomic neuropathies [1]. Patients with diabetes mellitus may also have an increased risk of developing mononeuropathies at common compression sites [2]. The most common entrapment neuropathy encountered in diabetic patients is carpal tunnel syndrome (30\%), and the second most common is ulnar neuropathy at the elbow (2.1\%) [2]. Epidemiologic and electrophysiologic studies of ulnar neuropathy at the elbow in diabetic patients are rare unlike those of carpal tunnel syndrome [3-5]. 
The ulnar neuropathy at the elbow in the presence of DPN may be difficult to diagnose using conduction slowing in the elbow segment as the motor conduction velocity (MCV) could be often decreased throughout the entire ulnar nerve. Although there is a focal abnormal conduction delay in the elbow segment of the ulnar nerve, symptoms and signs of ulnar neuropathy may not be present in patients with diabetes mellitus, especially in those with DPN. Hawley and Capobianco [6] suggested that it is impossible to establish ulnar MCV for diagnosing ulnar neuropathy at the elbow in patients with DPN. In particular, in patients with the forearm segment MCV less than $50 \mathrm{~m} / \mathrm{s}$, making diagnostic criteria for ulnar neuropathy at the elbow can be extremely challenging. Although we do not have definite criteria for ulnar neuropathy at the elbow in patients with diabetes mellitus, electrophysiologic studies including the inching test of the ulnar nerve around the elbow could be helpful to understand changes in the ulnar nerve in diabetic patients with or without polyneuropathy. This study was designed to demonstrate the prevalence and characteristics of subclinical ulnar neuropathy at the elbow in diabetic patients.

\section{MATERIALS AND MEHTODS}

\section{Subjects}

From January 1, 2003 to December 31, 2012, among diabetic patients referred for electrophysiologic studies for the evaluation of DPN at the department of physical medicine and rehabilitation, those who underwent ulnar segmental motor nerve conduction studies and the inching test were recruited. Their medical records including clinical, laboratory, and electrophysiologic data were retrospectively analyzed. Clinical data included demographic data, duration of diabetes mellitus, subjective symptoms of polyneuropathy (muscle weakness in the limbs, unsteady walking, numbness, pain, burning feet, and other types of sensory impairment, such as touch, pain, and temperature), and associated diseases (diabetes, hypothyroidism, connective tissue diseases, trauma or degenerative disease of elbow). Patients were excluded if they had a history of previous elbow surgery or trauma, cervical spine disease or cervical radiculopathy, medical disease associated with polyneuropathy except diabetes mellitus, brachial plexopathy, or Martin-Gruber anastomosis and ulnar neuropathy at the wrist. The patients were divided into two groups according to the presence of DPN.

\section{Methods}

Nerve conduction study was performed in the median nerve, ulnar, peroneal, tibial, superficial peroneal sensory and sural nerves. In evaluating the ulnar nerve, the patient held his/her palm upwards and flexed the elbow $90^{\circ}$. Stimulation was given at the wrist, $3 \mathrm{~cm}$ distal to the medial epicondyle (ME) and $7 \mathrm{~cm}$ proximal to the $\mathrm{ME}$. Compound muscle action potentials (CMAPs) of the ulnar nerve were recorded at the abductor digiti minimi (ADM) muscle using surface electrodes of $2 \mathrm{~cm}$ in diameter. If the CMAP was unobtainable, the first dorsal interosseous (FDI) muscle was used instead. Latency was measured automatically by Nicolet Viking IV Electrodiagnostic System (Nicolet Instrument Corporation, Madison, WI, USA) at the onset of the CMAP and the amplitude were measured from baseline to the negative peak.

The inching test was done with ADM or FDI recording to detect abnormal focal slowing of the ulnar nerve using TenElectrodes $[7,8]$. The ulnar nerve was excited at every $1 \mathrm{~cm}$ interval between distal $4 \mathrm{~cm}$ to the ME and proximal $3 \mathrm{~cm}$ to the ME, providing 8 measurements. Latency was automatically measured by the electromyography (EMG) machine at the initial negative onset point of the CMAP on the screen with a sweep speed of $0.1 \mathrm{~ms}$ and a sensitivity of $2 \mathrm{mV}$ per division. The upper normal limit of latency difference per $1 \mathrm{~cm}$ segment was $0.4 \mathrm{~ms}$ [7]. The skin temperature of the extremity was maintained above $34^{\circ} \mathrm{C}$.

The diagnosis of DPN was established if the suspected criteria were satisfied among the electrophysiologic criteria modified by Kwon et al. [9] after the Diabetes Control \& Complication Trials [10] (Table 1). As there were no criteria for the diagnosis of ulnar neuropathy at the elbow in patients with diabetes mellitus, we used the American Association of Neuromuscular \& Electrodiagnostic Medicine (AANEM) guidelines and the results of the inching test [11]. The AANEM guidelines were as follows: 1) Absolute MCV from above elbow (AE) to below elbow (BE) of less than $50 \mathrm{~m} / \mathrm{s}$ (AANEM1) and 2) An AE to BE segment greater than $10 \mathrm{~m} / \mathrm{s}$ slower than the $\mathrm{BE}$ to the wrist segment (AANEM2) [12].

Ulnar neuropathy at the elbow was classified into two categories according to the lesion location: retrocondylar 
lesion, lesion above the ME; humeroulnar arcade lesion, and lesion below the ME.

If the absolute MCV of the BE to the wrist (forearm) segment was less than $50 \mathrm{~m} / \mathrm{s}$, the AANEM1 can be useless. In these patients, the diagnosis was established based on the AANEM2 or the results of the inching test. We compared the demographic data, parameters of the ulnar nerve conduction study and diagnostic criteria for ulnar neuropathy between the two groups with and without DPN. The two groups with and without DPN were

Table 1. Modified electrodiagnostic criteria for diabetic polyneuropathy

\begin{tabular}{|c|c|}
\hline \multicolumn{2}{|c|}{ Diagnostic criteria } \\
\hline Sural SNAP amplitude & $\leq 5 \mu \mathrm{V}$ \\
\hline $\begin{array}{l}\text { Median SNAP } \\
\text { amplitude }\end{array}$ & $\leq 10 \mu \mathrm{V}$ \\
\hline $\begin{array}{l}\text { Peroneal CMAP } \\
\text { amplitude }\end{array}$ & $<1 \mathrm{mV}$ \\
\hline $\begin{array}{r}\text { Peroneal nerve } \\
\text { distal latency }\end{array}$ & $\begin{array}{l}\text { Distal latency } \geq 6 \mathrm{~ms} \text { or } \\
\mathrm{NCV}<40 \mathrm{~m} / \mathrm{s}\end{array}$ \\
\hline Peroneal F latency & Absent or $>5 \mathrm{~ms}$ \\
\hline H reflex & Absent \\
\hline Needle EMG & $\begin{array}{l}\text { Fibrillations in lower extremi- } \\
\text { ty muscles (TA,GCM, etc.) }\end{array}$ \\
\hline $\begin{array}{l}\text { SNAP, sensory nerve ac } \\
\text { muscle action potentia } \\
\text { ity; EMG, electromyogr } \\
\text { GCM, gastrocnemius n } \\
\text { sural plus at least two } \\
\text { pected plus two of ab } \\
\text { plus any of above list; D }\end{array}$ & $\begin{array}{l}\text { Ion potential; CMAP, compound } \\
\text {;CV, nerve conduction veloc- } \\
\text { phy; TA, tibialis anterior muscle; } \\
\text { edialis muscle; suspected DPN, } \\
\text { f above list; probable DPN, sus- } \\
\text { ve list; definite DPN, probable } \\
\text { N, diabetic polyneuropathy. }\end{array}$ \\
\hline
\end{tabular}

subdivided into two groups according to the MCV of the forearm, one with MCV greater than or equal to $50 \mathrm{~m} / \mathrm{s}$, and the other less than $50 \mathrm{~m} / \mathrm{s}$. We counted the number of cases meeting the three diagnostic criteria (AANEM1, AANEM2, and inching test) of ulnar neuropathy in each group. The prevalence of ulnar neuropathy according to the criteria was also compared.

\section{Statistics}

Statistical analysis was performed with SPSS software version 14.0 (SPSS Inc., Chicago, IL, USA). The chi-square test and independent t-test were used to compare demographic data, diagnostic criteria and electrophysiologic parameters between each group. The Mann-Whitney U test was used to compare the MCV, the CMAP of the AE and $\mathrm{BE}$, distal ulnar motor latency, and the parameters of sensory conduction study. Fisher exact test was used to compare the demographic data and diagnostic criteria when the number of cells with an expected frequency of less than 5 was $25 \%$ or more. The significance level was set at 0.05 .

\section{RESULTS}

\section{Demographic data}

Two hundred ten arms in 105 patients (50 men and 55 women; mean age $55.9 \pm 12.9$ years) with diabetes mellitus were analyzed. The mean duration of diabetes was 92.6 months (mean \pm standard deviation, 92.6 \pm 91.7$)$. Sixty patients were diagnosed with DPN. There was no significant difference in mean age and sex variation between the no DPN group and the DPN group. However, the duration of

Table 2. Demographic data

\begin{tabular}{lccc}
\hline & No DPN group $(\mathbf{n}=\mathbf{4 5})$ & DPN group $(\mathbf{n}=\mathbf{6 0})$ & p-value* \\
\hline Arms & 90 & 120 & - \\
\hline Sex (female:male) & $23: 22$ & $32: 28$ & 0.82 \\
\hline Age (yr) & $54.2 \pm 13.2$ & $57.2 \pm 12.5$ & 0.09 \\
DM duration (mo) & $45.5 \pm 61.2$ & $126.8 \pm 95.9$ & $<0.001$ \\
\hline DPN symptoms & 14 & 36 & 0.003 \\
Symptoms duration (mo) & $7.0 \pm 19.6$ & $20.1 \pm 33.9$ & 0.001 \\
Ulnar neuropathy symptoms & 0 & 0 & \\
HbAlC & $8.0 \pm 2.3$ & $9.4 \pm 2.7$ & 0.01 \\
\hline
\end{tabular}

Values are presented as mean \pm standard deviation or number.

DM, diabetes mellitus; DPN, diabetic polyneuropathy; HbAlC, glycosylated hemoglobin.

${ }^{*} \mathrm{p}<0.05$, significant differences exists between DPN group and no DPN group. 
diabetes, existence of DPN symptoms, duration of symptoms, and HbAlC (glycosylated hemoglobin which examined closest date to EMG) showed significantly larger values in the DPN group $(\mathrm{p}<0.05)$. There was no patient who had symptoms of ulnar neuropathy (weakness in the ulnar innervated muscles, paresthesia/numbness in the fourth and fifth digits) among patients referred for screening for DPN (Table 2).

\section{Electrophysiologic data}

The results of the nerve conduction study in the no DPN group and the DPN group are shown in Table 3. There was a statistically significant difference in the parameters of ulnar nerve conduction study between the

Table 3. Comparison of ulnar nerve conduction parameters according to DPN

\begin{tabular}{|c|c|c|c|}
\hline & No DPN group $(n=90)$ & DPN group $(n=120)$ & p-value* \\
\hline \multicolumn{4}{|l|}{ Motor } \\
\hline \multicolumn{4}{|l|}{$\mathrm{CV}(\mathrm{m} / \mathrm{s})$} \\
\hline $\mathrm{AE}$ to $\mathrm{BE}$ (elbow) & $58.6 \pm 3.9$ & $51.8 \pm 4.9$ & $<0.001^{\text {a) }}$ \\
\hline BE to wrist (forearm) & $56.3 \pm 6.1$ & $46.7 \pm 7.4$ & $<0.001$ \\
\hline \multicolumn{4}{|l|}{ Amplitude (mV) } \\
\hline Wrist & $10.9 \pm 2.1$ & $9.2 \pm 2.2$ & $<0.001$ \\
\hline $\mathrm{BE}$ & $10.1 \pm 2.1$ & $8.5 \pm 2.2$ & $<0.001^{\mathrm{a})}$ \\
\hline $\mathrm{AE}$ & $10.0 \pm 2.1$ & $8.1 \pm 2.2$ & $<0.001^{\text {a) }}$ \\
\hline Distal latency (ms) & $3.1 \pm 0.3$ & $3.6 \pm 0.4$ & $<0.001^{\text {a) }}$ \\
\hline \multicolumn{4}{|l|}{ Sensory } \\
\hline \multicolumn{4}{|l|}{ Latency (ms) } \\
\hline Onset & $2.5 \pm 0.2$ & $2.7 \pm 0.9$ & $<0.001^{\text {a) }}$ \\
\hline Peak & $3.3 \pm 0.2$ & $3.5 \pm 1.0$ & $<0.001^{\text {a) }}$ \\
\hline Amplitude $(\mu \mathrm{V})$ & $31.0 \pm 11.7$ & $13.6 \pm 8.0$ & $<0.001^{\text {a) }}$ \\
\hline
\end{tabular}

Values are presented as mean \pm standard deviation.

DPN, diabetic polyneuropathy; CV, conduction velocity; AE, above elbow; BE, below elbow.

${ }^{*} \mathrm{p}<0.05$, significant differences exists between DPN group and no DPN group.

${ }^{a)}$ Mann-Whitney test was done because normal distribution cannot be assumed.

Table 4. Comparison of criteria for ulnar neuropathy at the elbow (UNE) according to DPN and MCV of the forearm $(>50$ and $<50 \mathrm{~m} / \mathrm{s}$ )

\begin{tabular}{|c|c|c|c|c|c|c|c|c|c|}
\hline & \multicolumn{3}{|c|}{ Normal forearm segment ( $\geq 50 \mathrm{~m} / \mathrm{s}$ ) } & \multicolumn{3}{|c|}{ Slow forearm segment $(<50 \mathrm{~m} / \mathrm{s})$} & \multicolumn{3}{|c|}{ Total } \\
\hline & $\begin{array}{c}\text { No DPN } \\
(n=89)\end{array}$ & $\begin{array}{c}\text { DPN } \\
(n=81)\end{array}$ & p-value* & $\begin{array}{c}\text { No DPN } \\
(n=1)\end{array}$ & $\begin{array}{c}\text { DPN } \\
(n=39)\end{array}$ & p-value* & $\begin{array}{c}\text { No DPN } \\
(n=90)\end{array}$ & $\begin{array}{c}\text { DPN } \\
(n=120)\end{array}$ & p-value* \\
\hline AANEM1 & $6(6.7)$ & $42(35.0)$ & $<0.001$ & 0 & $33(84.6)$ & $0.125^{\mathrm{b})}$ & 6 & 77 & $<0.001$ \\
\hline AANEM2 & $5(5.6)$ & $12(10.0)$ & 0.03 & 0 & $5(4.2)$ & $1.00^{\mathrm{b})}$ & 5 & 17 & 0.03 \\
\hline Inching test & 0 & $10(8.3)$ & $0.003^{b)}$ & 0 & $12(10.0)$ & $1.00^{\mathrm{b})}$ & 0 & 22 & $<0.001$ \\
\hline $\mathrm{UNE}^{\mathrm{a})}$ & $10(11.1)$ & $42(35.0)$ & $<0.001$ & 0 & $13(10.8)$ & $1.00^{\mathrm{b})}$ & $10(11.1)$ & $55(45.8)$ & $<0.001$ \\
\hline
\end{tabular}

Values are presented as number (\%).

DPN, diabetic polyneuropathy; MCV, motor conduction velocity; AANEM1, absolute MCV from above elbow (AE) to below elbow (BE) of less than $50 \mathrm{~m} / \mathrm{s}$; AANEM2, an AE-to-BE segment greater than $10 \mathrm{~m} / \mathrm{s}$ slower than the BE-to-wrist segment; forearm, motor conduction velocity of below elbow to wrist.

${ }^{*} \mathrm{p}<0.05$, significant differences exists between DPN group and no DPN group.

a) Ulnar neuropathy was diagnosed by AANEM1 or AANEM2 or inching test in subgroup with normal forearm segment $(\geq 50 \mathrm{~m} / \mathrm{s})$, but diagnosed by AANEM2 or inching test in subgroup with slow forearm segment $(<50 \mathrm{~m} / \mathrm{s})$. ${ }^{\text {b) }}$ Fisher exact test was done: the number of cells which expected frequency is less than 5 were $25 \%$ or more. 
two groups.

The numbers of cases that met the criteria for AANEM1, AANEM2, and the inching test for ulnar neuropathy at the elbow were 83 (39.5\%), 22 (10.5\%), and 22 (10.5\%) arms, respectively. There was a statistically significant difference in the number of cases that met the three diagnostic criteria between the no DPN group and the DPN group (Table 4). In the subgroup with normal forearm segment (MCV $\geq 50 \mathrm{~m} / \mathrm{s})$, all three diagnostic criteria showed statistically significant difference between the no
DPN group and the DPN group. Ulnar neuropathy at the elbow was observed in 42 arms (35.0\%) in the DPN group and 10 arms $(11.1 \%)$ in the no DPN group (Table 4$)$. In the subgroup with the slow forearm segment $(\mathrm{MCV}<50$ $\mathrm{m} / \mathrm{s}$ ), there was no significant difference in the number of cases meeting the three diagnostic criteria between patients with the no DPN group and the DPN group. As AANEM1 was not used for the diagnosis of ulnar neuropathy in patients with the slow forearm segment $(\mathrm{MCV}<50 \mathrm{~m} / \mathrm{s})$, ulnar neuropathy at the elbow was observed in 13 arms
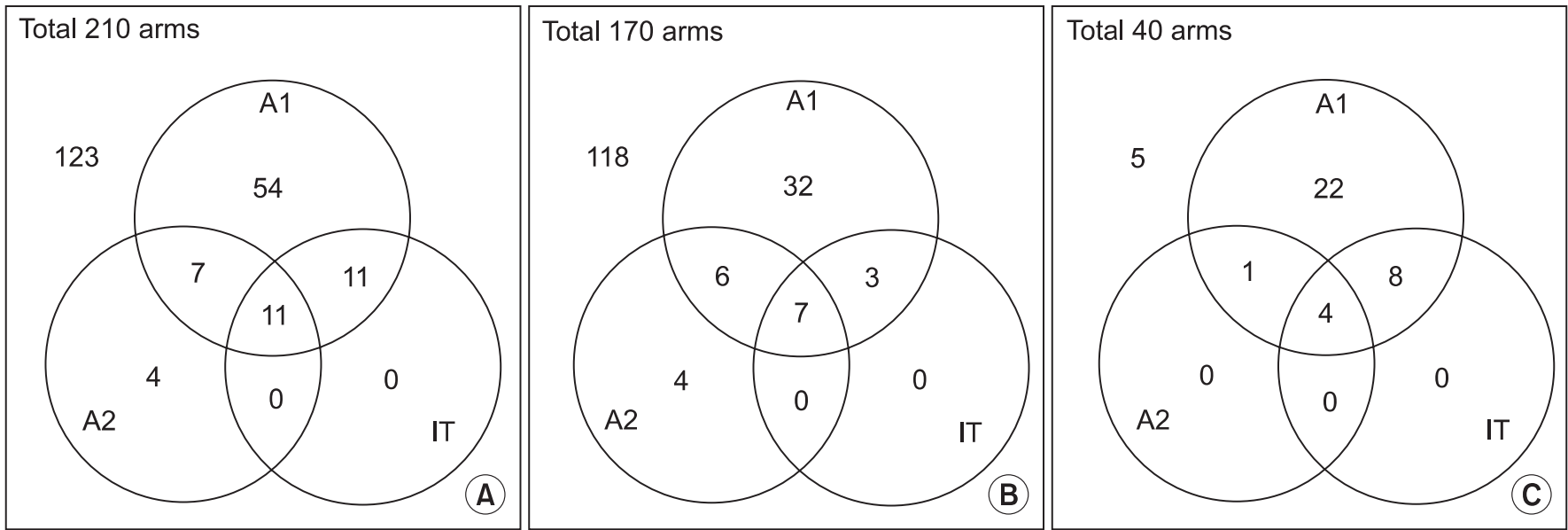

Fig. 1. Overlapping patients who satisfy each diagnostic criterion of ulnar neuropathy out of (A) all diabetic patients, in (B) the subgroup with the normal forearm segment $(\geq 50 \mathrm{~m} / \mathrm{s})$ and $(\mathrm{C})$ the subgroup with the slow forearm segment $(<50$ m/s). A1, AANEM1; A2, AANEM2; IT, inching test.

Table 5. Demographic and electrophysiologic difference according to MCV of the forearm segment in patients with DPN

\begin{tabular}{|c|c|c|c|}
\hline & \multicolumn{2}{|c|}{ UMCV at forearm } & \multirow{2}{*}{ p-value* } \\
\hline & $<50 \mathrm{~m} / \mathrm{s}(\mathrm{n}=39)$ & $\geq 50 \mathrm{~m} / \mathrm{s}(\mathrm{n}=81)$ & \\
\hline DM duration (mo) & $159.1 \pm 100.7$ & $111.4 \pm 89.9$ & 0.01 \\
\hline DPN symptoms & $31(79.5)$ & $43(52.4)$ & 0.005 \\
\hline Symptom duration (mo) & $22.6 \pm 39.9$ & $13.7 \pm 30.2$ & 0.18 \\
\hline HbAlC (\% of total $\mathrm{Hb})$ & $10.33 \pm 2.5$ & $8.78 \pm 2.5$ & 0.002 \\
\hline UMCV at elbow $(\mathrm{m} / \mathrm{s})$ & $41.0 \pm 4.8$ & $49.5 \pm 6.9$ & $<0.001^{\text {a) }}$ \\
\hline Ulnar neuropathy at the elbow & $13(33.3)$ & $42(51.9)$ & 0.087 \\
\hline AANEM1 & - & $42(51.9)$ & - \\
\hline AANEM2 & $5(12.8)$ & $10(12.3)$ & 0.643 \\
\hline Inching test & $12(30.8)$ & $10(12.3)$ & 0.015 \\
\hline
\end{tabular}

Values are presented as mean \pm standard deviation or number $(\%)$.

UMCV, ulnar motor conduction velocity; DM, diabetes mellitus; DPN, diabetic polyneuropathy; HbAlC, glycosylated hemoglobin; AANEM1, absolute MCV from above elbow (AE) to below elbow (BE) of less than $50 \mathrm{~m} / \mathrm{s}$; AANEM2, an AE-to-BE segment greater than $10 \mathrm{~m} / \mathrm{s}$ slower than the BE-to-wrist segment.

${ }^{*} \mathrm{p}<0.05$, significant differences exists between DPN group and no DPN group.

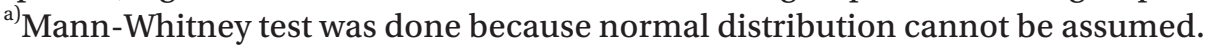


(10.8\%) in the DPN group and 0 arms $(0 \%)$ in the no DPN group (Table 4).

Some cases accorded with more than one diagnostic criteria. Among 83 arms which met the criteria of AANEM1, 22 arms (26.5\%) met the criteria of AANEM2. Twenty-two arms (26.5\%) were found to be abnormal in the inching test (Fig. 1A). Among 48 arms which met the criteria of AANEM1 in the normal forearm MCV group (170 arms), $13 \mathrm{arms}(27.1 \%)$ met the criteria of AANEM2, and 10 arms (20.8\%), the abnormal inching test (Fig. 1B). Among five arms which met the criteria of AANEM2 in the group (40 arms) with the slow forearm segment $(\mathrm{MCV}<50 \mathrm{~m} / \mathrm{s}), 4$ cases $(80.0 \%)$ showed abnormal results in the inching test (Fig. 1C). Patients with the slow forearm segment $(\mathrm{MCV}<50 \mathrm{~m} / \mathrm{s})$ in the DPN group had a significantly longer duration of diabetes mellitus $(p=0.01)$, higher HbAlc and slower MCV of the elbow segment $(p<0.001)$ compared to those with the normal forearm segment (MCV>50 m/s). In the slow forearm segment group, DPN symptoms $(\mathrm{p}=0.005)$ and abnormal results from the inching test $(\mathrm{p}=0.02)$ were more prevalent compared to the normal forearm segment group. The duration of symptoms also tended to be longer in the

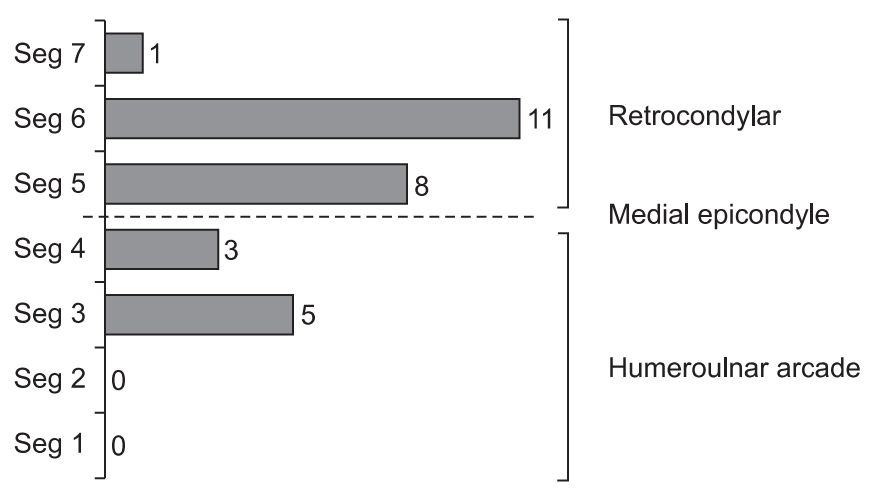

Fig. 2. Ulnar neuropathy lesion site which identified by the inching test. The most common lesion site was the retrocondylar groove (20 arms, $69.6 \%)$, and the second common site was the humeroulnar arcade ( $8 \mathrm{arms}$, $21.8 \%$ ). Dual lesions including the retrocondylar and humeroulnar arcade lesions were found in 2 arms (8.7\%). Segl, segment between 3 and $4 \mathrm{~cm}$ distal to the medial epicondyle (ME); Seg2, segment between 2 and $3 \mathrm{~cm}$ distal to ME; Seg3, segment between 1 and $2 \mathrm{~cm}$ distal to $\mathrm{ME}$; Seg4, segment between ME and $1 \mathrm{~cm}$ distal to ME; Seg5, segment between ME and $1 \mathrm{~cm}$ proximal to ME; Seg6, segment between 1 and $2 \mathrm{~cm}$ proximal to ME; Seg7, segment between 2 and $3 \mathrm{~cm}$ proximal to ME. slow forearm segment group, even though there was no statistically significant difference (Table 5). Based on the results of the inching test (upper normal limit of latency difference per $1 \mathrm{~cm}$ segment, $0.4 \mathrm{~ms}), 16$ arms (69.6\%) had retrocondylar lesions, and 5 arms (21.8\%) humeroulnar arcade lesions. Dual lesions including retrocondylar and humeroulnar arcade lesions were noted in 2 arms (8.7\%) (Fig. 2).

\section{DISCUSSION}

When performing nerve conduction studies to diagnose DPN, we often encounter electrophysiologic findings suggestive of asymptomatic ulnar neuropathy or carpal tunnel syndrome. However, it is challenging to diagnose subclinical ulnar neuropathy or carpal tunnel syndrome in patients with DPN. In the case of carpal tunnel syndrome, the condition can be differentiated by measuring the latency difference between the ulnar motor nerve and the median motor nerve with 1st palmar interosseous and 2nd lumbrical muscle recordings $[13,14]$. Although ulnar neuropathy is the second most common entrapment neuropathy $(2.1 \%)$ in diabetic patients [2], there are yet no special electrophysiologic criteria to identify focal lesions of the ulnar nerve. Therefore, MCV delay in line with the AANEM guidelines has been used for the diagnosis of ulnar neuropathy at the elbow in patients with diabetes mellitus. Decreased amplitude (conduction block) or different shapes of the waveform of CMAPs between above and below elbow, and decreased amplitude of sensory nerve action potentials can be used as important indicators of ulnar neuropathy at the elbow [12]. However, the latter two findings are easily affected if they are associated with DPN. Since sensory alterations are noted prior to significant changes in motor conduction studies in diabetic patients with polyneuropathy [15], the results of sensory conduction studies were excluded from the diagnostic criteria of ulnar neuropathy in our study. However, when the MCV of the ulnar nerve is decreased in the elbow without any symptoms, it is difficult to know whether the result is meaningful or not. There is no international consensus concerning the sensitivity and specificity of the AANEM criteria in diagnosing ulnar neuropathy. The cutoff values of the electrophysiologic parameters suggested by the AANEM guidelines are also under debate. Therefore, in this study, the inching test 
was additionally performed to diagnose ulnar neuropathy at the elbow. The inching test is a popular test performed to localize the lesion site of ulnar neuropathy at the elbow with high sensitivity of detection $[7,11]$.

In this study, the prevalence of DPN was $57.1 \%$. The exact prevalence of any form of polyneuropathy among diabetic patient is not accurately known but has been estimated as $5 \%-66 \%[1,16]$. Diabetic patients with polyneuropathy had more uncontrolled and long-standing diabetes mellitus and symptoms of polyneuropathy compared to those without polyneuropathy. These result coincided with those of previous researchers $[1,16]$.

Also in our study, the prevalence of the ulnar neuropathy at the elbow in the DPN group was higher than that in the no DPN group. This increased susceptibility to nerve compression is probably multifactorial because of repetitive undetected trauma and metabolic causes, which may increase endoneurial edema and vascular changes of the vasa nervorum causing nerve ischemia [3].

Interestingly, in our study, all the patients with ulnar neuropathy were asymptomatic. In the majority of patients with ulnar neuropathy in the general population, initial symptoms are typically intermittent numbness and tingling sensation in ulnar nerve distribution. Motor weakness may not be noted for months or years [11]. However, a previous report on severe ulnar neuropathy in patients with diabetes mellitus revealed that motor deficits outweighed sensory involvement [3], which might be associated with increased sensory threshold in diabetic patient with polyneuropathy [17]. In diabetic patients with subclinical ulnar neuropathy at the elbow, motor symptoms and signs including the weakness in gripping the objects and atrophy of the hand intrinsic muscles could be developed later without sensory symptoms [11]. Also, it may be important to recognize subclinical ulnar neuropathy at the elbow and to avoid risk factors, such as external compression or persistent elbow flexion, in diabetic patients. As studies about subclinical or clinical ulnar neuropathy at the elbow have rarely been established in diabetic patients and its clinical implications have not been elucidated yet, further assessments including follow-up clinical and electrophysiologic studies are needed.

Without the inching test was not performed, 8 of 13 cases (61.5\%) of ulnar neuropathy would have been missed (Fig. 1C). Therefore, when forearm MCV slowing exists in patients with DPN, the inching test is helpful in diagnosing ulnar neuropathy at the elbow even if the condition is subclinical.

The most common location for ulnar mononeuropathy at the elbow is the retrocondylar groove, and the second common is humeroulnar arcade [11]. In a study using the inching test conducted in symptomatic ulnar neuropathy patients without polyneuropathy, retrocondylar groove compression was more common (54.2\%) than humeroulnar arcade compression (29.2\%), and dual lesion was the least common (16.6\%) [7]. The incidence was also same in DPN group of our study. The most common lesion site was the retrocondylar groove (69.6\%) and the second common site was the humeroulnar arcade (21.8\%). Dual lesions including the retrocondylar and humeroulnar arcade lesions were found in 2 arms (8.7\%).

The usual common bias of retrospective studies was partially reduced in our study because we used the same standardized report to collect data. In particular, the electrophysiologic protocol was consistent throughout the study, and the same neurophysiologist performed the entire inching test using the same equipment.

In conclusion, these findings demonstrate that ulnar neuropathy at the elbow is more common in patients with DPN even if they are asymptomatic. In addition, if the MCV of both elbow (AE to BE) and forearm (BE to wrist) segments are decreased to less than $50 \mathrm{~m} / \mathrm{s}$, it may be useful to apply the AANEM2 criteria and the inching test to diagnose ulnar neuropathy caused by focal ulnar nerve entrapment at the elbow.

\section{CONFLICT OF INTEREST}

No potential conflict of interest relevant to this article was reported.

\section{REFERENCES}

1. Partanen J, Niskanen L, Lehtinen J, Mervaala E, Siitonen O, Uusitupa M. Natural history of peripheral neuropathy in patients with non-insulin-dependent diabetes mellitus. N Engl J Med 1995;333:89-94.

2. Vinik A, Mehrabyan A, Colen L, Boulton A. Focal entrapment neuropathies in diabetes. Diabetes Care 2004;27:1783-8.

3. Schady W, Abuaisha B, Boulton AJ. Observations on 
severe ulnar neuropathy in diabetes. J Diabetes Complications 1998;12:128-32.

4. Acosta JA, Hoffman SN, Raynor EM, Nardin RA, Rutkove SB. Ulnar neuropathy in the forearm: a possible complication of diabetes mellitus. Muscle Nerve 2003;28:40-5.

5. Mondelli M, Aretini A, Rossi S. Ulnar neuropathy at the elbow in diabetes. Am J Phys Med Rehabil 2009;88:278-85.

6. Hawley J, Capobianco J. Localizing ulnar nerve lesions by motor nerve conduction study. Electromyogr Clin Neurophysiol 1987;27:385-92.

7. Kim DH, Kang YK, Hwang M, Jo HS, Kim KH. Localization of ulnar neuropathy at the elbow using new stimulator for the inching test. Clin Neurophysiol 2004;115:1021-6.

8. Kim DH, Kwon HK, Kwon KH, Kim WK, Kim CH. An evidence-based electrodignositc guidelines for the diagnosis of diabetic sensory and motor polyneuropathy. J Korean Assoc EMG Electrodiagn Med 2012;14:47-54.

9. Kwon HK, Kim L, Park YK, Lee HJ. Frequency of carpal tunnel syndrome according to the severity of diabetic neuropathy. J Korean Acad Rehabil Med 2005;29:272-5.

10. The Diabetes Control and Complications Trial Research Group. The effect of intensive diabetes therapy on the development and progression of neuropathy. Ann Intern Med 1995;122:561-8.

11. Landau ME, Campbell WW. Clinical features and ele- ctrodiagnosis of ulnar neuropathies. Phys Med Rehabil Clin N Am 2013;24:49-66.

12. American Association of Electrodiagnostic Medicine; American Academy of Neurology; American Academy of Physical Medicine and Rehabilitation. Practice parameter for electrodiagnostic studies in ulnar neuropathy at the elbow: summary statement. Muscle Nerve 1999;22:408-11.

13. Boonyapisit K, Katirji B, Shapiro BE, Preston DC. Lumbrical and interossei recording in severe carpal tunnel syndrome. Muscle Nerve 2002;25:102-5.

14. Park DS, Nam HS, Lee SE, Kim DH, Lee JG, Jeong HO. The usefulness of various electrodiagnostic parameters in mild carpal tunnel syndrome. J Korean Assoc EMG Electrodiagn Med 2008;10:135-43.

15. Dumitru D, Amato AA, Zwarts MJ. Electrodiagnostic medicine. 2nd ed. Philadelphia, PA: Hanley \& Belfus; 2002.

16. Dyck PJ, Kratz KM, Karnes JL, Litchy WJ, Klein R, Pach JM, et al. The prevalence by staged severity of various types of diabetic neuropathy, retinopathy, and nephropathy in a population-based cohort: the Rochester Diabetic Neuropathy Study. Neurology 1993;43:817-24.

17. Bergenheim T, Borssen B, Lithner F. Sensory thresholds for vibration, perception and pain in diabetic patients aged 15-50 years. Diabetes Res Clin Pract 1992;16:47-52. 